\title{
Service Experience of the Elderly in Nursing Homes with Integration of Medical and Nursing in Chongqing: A Qualitative Study
}

\author{
Wenxia Li1 ${ }^{1,2,3 *}$, Xue Du',2,3*, Qian Peng ${ }^{1,2,3}$, Wenfen Zhu', Jun Ma1,2,3\# \\ ${ }^{1}$ School of Public Health and Management, Chongqing Medical University, Chongqing, China \\ ${ }^{2}$ Research Center for Medicine and Social Development, Chongqing Medical University, Chongqing, China \\ ${ }^{3}$ Collaborative Innovation Center of Social Risks Governance in Health, Chongqing Medical University, Chongqing, China \\ ${ }^{4}$ School of Nursing, Chongqing Medical University, Chongqing, China \\ Email: "fairlily1117@163.com
}

How to cite this paper: Li, W.X., Du, X., Peng, Q., Zhu, W.F. and Ma, J. (2021) Service Experience of the Elderly in Nursing Homes with Integration of Medical and Nursing in Chongqing: A Qualitative Study. Open Access Library Journal, 8: e7736. https://doi.org/10.4236/oalib.1107736

Received: July 6, 2021

Accepted: September 13, 2021

Published: September 16, 2021

Copyright $\odot 2021$ by author(s) and Open Access Library Inc.

This work is licensed under the Creative Commons Attribution International License (CC BY 4.0).

http://creativecommons.org/licenses/by/4.0/

\section{(c) (i) Open Access}

\begin{abstract}
To deeply understand the service experience and development expectations of the elderly in nursing homes with integration of medical and nursing in Chongqing so as to provide reference for improving medical-nursing integrated services in nursing homes. We used phenomenological research method and interviewed 16 elderly people from 3 nursing homes with semi-structured in-depth interview, then analyzed the interview data with Colaizzi 7-step analysis method. Four themes were refined, they are construction of living environment, daily living care, medical service provision, psychological support. There are currently many shortcomings in medical-nursing integrated services of nursing homes, which cannot meet the needs of the elderly. Therefore, we recommended the following four measures to improve services so as to increase the satisfaction of the elderly: Firstly, clarify the content of medical services and improve the level of medical services; secondly, increase emotional and social support and establish a psychological counseling department; thirdly, introduce professional talent team in elderly nursing and strengthen knowledge and skills training of carer; fourthly, have a scientific guidance for rational diet and provide diversified diet.
\end{abstract}

\section{Subject Areas \\ Social Medicine}

\footnotetext{
*These authors contributed equally to this work.

\#Corresponding author.
} 


\section{Keywords}

Service Experience, Integration of Medical and Nursing, Nursing Homes, Qualitative Study

\section{Introduction}

According to Statistical Bulletin of National Economic and Social Development in 2019, the elderly aged 60 and above in China accounted for $18.1 \%$, and the elderly aged 65 and above accounted for 12.6\% [1]. Meanwhile, the population aged 60 and above accounted for $20.6 \%$ in Chongqing, and the population aged 65 and above accounted for $14.96 \%$ in Chongqing [2], indicating that the population aging has become very serious in Chongqing. In order to handle the population aging effectively, Chongqing has actively responded to the call for national reforms and has successively issued policies related to medical-nursing integrated services. There are currently three main pension modes in China, they are family pension, institutional pension and home-based community pension, however, traditional family pension functions are gradually weakening and home-based community pension services are not yet perfect, hence institutional pension has become an important way to solve the pension problem [3] [4]. So far, however, medical-nursing integrated services in nursing homes cannot meet the needs of the elderly, and the quality of service needs to be improved [5]. Given that, this research is based on the perspective of the elderly, adopts qualitative research methods, and deeply explores elder people's real experience and development expectations of medical-nursing integrated services in nursing homes, in order to discover potential problems in medical-nursing integrated services of nursing homes and provide reference for improving medical-nursing integrated services.

\section{Objects and Methods}

\subsection{Research Objects}

We adopted the purpose sampling method, and selected elderly people of two large nursing homes (nursing homes have hospitals and support medical insurance payments) in Chongqing as the research objects to conduct semi-structured in-depth interview from December 2019 to January 2020. Inclusive criteria: 1) Age $\geq 60$; 2) The time of admission to nursing homes $\geq 3$ months; 3 ) No severe hearing and vision impairment; 4) Ability to express the information needed for the investigation clearly.

The sample size was determined based on the principle of information saturation, until repeated interview information appeared. In the end, a total of 16 elderly people were enrolled, with an average age of $84.25 \pm 6.46$ years old, and elderly people mainly suffered from common chronic diseases, such as diabetes, hypertension, cardiovascular and cerebrovascular diseases and osteoarthritis. 
The basic information of 16 interviewees is shown in Table 1.

\subsection{Methods}

\subsubsection{Data Collection}

Based on literature review, expert consultation and pre-interview, we finally determined the semi-structured interview outline of the elderly. The main contents of the interview outline are listed as follows: 1) Basic information of the elderly; 2) The time and reason of living in nursing homes; 3 ) What is the overall feeling of living in nursing homes? 4) What kind of medical-nursing integrated services are provided by nursing homes? Are you satisfied with these services? 5) What are your opinions and suggestions medical-nursing integrated services in nursing homes? The interviewers informed the interviewees of research purpose

Table 1. General information of 16 interviewees.

\begin{tabular}{|c|c|c|c|c|c|c|c|}
\hline No. & Gender & Age & $\begin{array}{l}\text { Marital } \\
\text { status }\end{array}$ & $\begin{array}{c}\text { Literacy } \\
\text { levels }\end{array}$ & $\begin{array}{c}\text { Career before } \\
\text { retirement }\end{array}$ & $\begin{array}{c}\text { Number of } \\
\text { confirmed } \\
\text { diseases }\end{array}$ & $\begin{array}{c}\text { Whether } \\
\text { have health } \\
\text { insurance }\end{array}$ \\
\hline A1 & Female & 70 & Divorced & Junior college & Teacher & 5 & Yes \\
\hline $\mathrm{A} 2$ & Female & 91 & Married & Junior college & $\begin{array}{l}\text { Company } \\
\text { employee }\end{array}$ & 3 & Yes \\
\hline A3 & Male & 82 & Married & $\begin{array}{c}\text { Secondary } \\
\text { school }\end{array}$ & Civil servant & 3 & Yes \\
\hline $\mathrm{A} 4$ & Female & 82 & Widowed & $\begin{array}{c}\text { Elementary } \\
\text { school }\end{array}$ & Worker & 4 & Yes \\
\hline A5 & Female & 80 & Divorced & $\begin{array}{c}\text { Secondary } \\
\text { school }\end{array}$ & Worker & 0 & Yes \\
\hline A6 & Female & 80 & Married & $\begin{array}{c}\text { Secondary } \\
\text { school }\end{array}$ & Teacher & 4 & Yes \\
\hline A7 & Male & 91 & Widowed & $\begin{array}{c}\text { Senior middle } \\
\text { school }\end{array}$ & $\begin{array}{c}\text { Civil } \\
\text { servant }\end{array}$ & 1 & Yes \\
\hline A8 & Female & 88 & Widowed & $\begin{array}{c}\text { Junior high } \\
\text { school }\end{array}$ & Worker & 4 & Yes \\
\hline A9 & Female & 88 & Married & $\begin{array}{c}\text { Secondary } \\
\text { school }\end{array}$ & $\begin{array}{c}\text { Civil } \\
\text { servant }\end{array}$ & 0 & Yes \\
\hline A10 & Male & 84 & Married & $\begin{array}{l}\text { Bachelor } \\
\text { Degree }\end{array}$ & Teacher & 1 & Yes \\
\hline A11 & Female & 98 & Widowed & $\begin{array}{c}\text { Junior high } \\
\text { school }\end{array}$ & $\begin{array}{c}\text { Civil } \\
\text { servant }\end{array}$ & 1 & Yes \\
\hline $\mathrm{A} 12$ & Female & 76 & Widowed & $\begin{array}{c}\text { Secondary } \\
\text { school }\end{array}$ & $\begin{array}{c}\text { Civil } \\
\text { servant }\end{array}$ & 1 & Yes \\
\hline A13 & Female & 86 & Widowed & $\begin{array}{c}\text { Senior middle } \\
\text { school }\end{array}$ & $\begin{array}{c}\text { Civil } \\
\text { servant }\end{array}$ & 4 & Yes \\
\hline A14 & Female & 87 & Widowed & $\begin{array}{l}\text { Junior } \\
\text { college }\end{array}$ & Doctor & 4 & Yes \\
\hline A15 & Male & 86 & Married & $\begin{array}{l}\text { Senior middle } \\
\text { school }\end{array}$ & Worker & 1 & Yes \\
\hline A16 & Female & 79 & Married & $\begin{array}{c}\text { Elementary } \\
\text { school }\end{array}$ & Worker & 1 & Yes \\
\hline
\end{tabular}


and significance, promised the confidentiality of the interview in advance, then conducts face-to-face in-depth interviews after obtaining informed consent. The interview time for each person is 40 - 60 minutes, and the interview contents are well recorded and saved by recording.

\subsubsection{Data Analysis}

The Colaizi 7-step analysis method consists of seven steps, namely familiarization, identifying significant statements, formulating meanings, clustering themes, developing an exhaustive description, producing the fundamental structure, and seeking verification of the fundamental structure [6]. We transcribed the interview recordings into text materials within 24 hours after the interview, and strictly followed these seven steps to analyze the interview data so as to ensure the completeness, authenticity and credibility of the research results [6].

\section{Results}

Four themes were refined after being sorted, they are construction of living environment, daily living care, medical service provision, psychological support.

\subsection{Theme 1: The Construction of Living Environment}

\subsubsection{Natural Environment}

For the elderly in nursing homes, environmental conditions of nursing homes will affect the quality of life of the elderly [7], and it is also a necessary consideration for the elderly and their families to choose a nursing home. A6: "I have lived in the nursing home for more than 3 months. I choose this nursing home because of its good environment. My husband and I often take a walk in the nursing home." A11: "This nursing home is far away from the city, green and fresh air, so the body will be healthier. Most people come to here for its environment."

\subsubsection{Layout and Facilities}

As the second place of the elderly, the cleanliness of room layout and the completeness of facilities are the primary considerations before they move into nursing home [8]. A3: "The facilities here are very good both inside and outside. There are fitness equipment, chess room, mahjong table outside the room, and there are air conditioners, water heaters, TVs, call bells in the room". A5: "The facilities are OK, I'm very satisfied. The room is spacious, with heating in winter. The summer is cool, so do not need to turn on air conditioner, but there are too few mahjong tables, too many people".

\subsection{Theme 2: Daily Living Care}

\subsubsection{Basic Living Service}

Basic living services are the key to service for the elderly. The reason why the elderly go to nursing homes is that most of them have difficulties in home-based care due to limited time and energy for their children, their old age and limited 
mobility. Previous researches show that the elderly in nursing homes value basic living services [9]. A9: "There are service staff here to help us fetch boiled water, do cleaning, wash the bedclothes and assist to walk. Their service is very attentive. In terms of food, there are not a wide variety of dishes, and the meal is scheduled too early, 7:10 in the morning, 11:10 at noon, 5:10 at night. Dinner is too early, so I'll be hungry in the evening". A10: "My wife and I have lived here for more than 3 years. The service staff helps us wash clothes, do cleaning, etc., but the food is getting worse and worse. There are not many varieties of dishes, and we often eat the same vegetables, and they do not wash vegetables carefully, so the food needs to be improved".

\subsubsection{Caregivers of Daily Life}

As providers of elderly care services, caregivers' quantity and quality will directly affect the satisfaction of the elderly. A6: "The caregivers here have a good working attitude and an affinity. They treat the elderly very well, like their own relatives. They will chat with us when they come to do cleaning, and they work very seriously, we are satisfied with them". A7: "My ability to walk is not convenient, so I live in the intermediate nursing area. There is one nurse on each floor of intermediate nursing area, the caregiver usually care for me. A caregiver has to care for 6 elderly people, they are too busy". A15: "The caregivers have a good service attitude, but they are not well-educated. Most of them are rural women around nursing homes, they don't know how to care for the elderly, and they have not received any training on the job, so their professional quality is not good".

\subsection{Theme 3: Medical Service Provision}

\subsubsection{Quality of Medical Service}

Of the 16 elderly people, 14 suffered from diagnosed disease with a prevalence rate of $87.5 \%$, which shows that the elderly have a very high demand for medical and health care.

A8: "The hospital in nursing home provides such services as seeing a doctor and hospitalization, and it also organize health talks, as well as traditional Chinese medicine and physical therapy, but medical technology is worse than that of hospital outside nursing home. I was hospitalized in the institution's hospital for 18 days due to a cough, but it has not been well. The frequency of blood pressure measurement is low, only once a week. I suffer from high blood pressure, nursing home should pay attention to it and monitor blood pressure at any time". A9: "The hospital can see a doctor and take medicine, but most elderly people are unwilling to go there, because they think its standard of medical care is not high. At the same time, there are not many doctors, and many doctors have resigned, the hospital can't retain talents".

\subsubsection{Restrictions on Medical Services}

The original intention of establishing hospital in nursing home is to facilitate the elderly to obtain professional medical services, but the reality is not optimistic, 
and there are still many restrictions on the medical services provision.A1: "I suffer from uremia and need dialysis twice a week, but the hospital in nursing home lacks dialysis equipment, so I have to pay for a ride from nursing home to other hospital for dialysis every time". A11: "My special disease medical insurance can only be reimbursed in the designated hospital, but it cannot be reimbursed in the hospital of nursing home. I took Chinese medicine in the hospital of nursing home for several times, the doctors are very responsible and enthusiastic. However, there were few kinds of drugs in the hospital and the prices were expensive, so I always went to the outside hospital to see the doctor".

\subsection{Theme 4: Psychological Support}

\subsubsection{Family Care}

As the elderly in nursing homes grow older, their various physiological functions gradually decline, and coupled with long-term separation from their families, they are more likely to experience anxiety, loneliness, and other negative psychology than those living at home [10], so they have a strong demand for family care. A1: "I still don't get used to this nursing home. I can't fall asleep every day since dialysis, I feel anxious and lonely all the time. My daughter is busy working in Shenzhen, and she hasn't come to see me since she sent me to the nursing home". A14: "As I get old, my personality has changed a bit. I feel depressed about a lot of things, my family is not around, I'm very lonely. When I see most of the elderly around me are sick, I feel very pessimistic about that. My children are usually busy at work, and they seldom came to see me, they just called to say a few words. In fact, I still want to go home and live with my children". A8: "I am very anxious recently. I have lost my husband, so I feel unhappy and lonely".

\subsubsection{Cultural and Recreational Activity}

Abundant cultural and recreational activities are beneficial to physical and mental health of the elderly, and many elderly people expressed the need for cultural and recreational activities to enrich their leisure life. A7: "There are many activities in nursing homes, such as playing ball, singing and dancing, watching movies, playing mahjong, etc. Now I don't participate in them due to my own health. I used to like to play everywhere. The activities are going well, but my body is not good enough to participate in them". A10: "No personnel organizes the activities. The singing and dancing are all spontaneously organized by the elderly, but not many people take part in them. I still hope that nursing homes can organize everyone to participate together". A12: “There are many activities in nursing home, and I feel very fulfilled. Now I'm sick, I can't take part in the mand I'm not used to it. I hope to get better soon".

\subsubsection{Psychological Consultation}

The elderly in nursing home often suffer from negative emotions such as loneliness and anxiety due to the absence of their children and the unfamiliarness of old people around them. However, there is no special psychological consultation service in nursing homes at present, so the psychological problems of the elderly 
cannot be solved. A8: "I suffer from depression, and I usually take medicine to control my random thoughts. The nursing home does not have psychological counseling services, and I have little contact with other elderly people, so I often don't know who to talk to". A9: "The nursing home does not have psychological counseling services, sometimes caregiver chats with us. Most of the elderly are lonely, so we hope to have professional staff to ease our emotions". A16: "It's okay for me to live in nursing home with my husband, and I don't feel lonely. Some elderly people live alone and children do not come to visit them often, so they are very lonely. The nursing home does not have psychological counseling services, we still need a professional psychologist".

\section{Discussion}

Medical-nursing integrated services of nursing homes cannot effectively meet the needs of the elderly at present. Therefore, improvements can be made from the following aspects to increase the service level of nursing homes.

\subsection{Clarify the Content of Medical Services and Improve the Level of Medical Services}

The research found that there were some deficiencies in hospitals of nursing homes at present, such as low medical level, lack of medical equipment and limitation of medical insurance payment. To solve above problems, hospitals in nursing homes should clarify the content of medical services, with a focus on prevention and management of chronic diseases, long-term rehabilitation nursing, emergency medical, health consultation and other medical needs of the elderly [11], highlighting their own characteristics. Then hospitals should allocate personnel and equipment in line with the service content to improve medical service capabilities. Meanwhile, hospitals in nursing homes should also moderately increase salary of medical staff, and focus on training, establish a rotation training system for medical staff, and promote professional skill appraisal in integration of medical and nursing [12] to enhance the professional skills of medical staff. Furthermore, nursing homes can sign a cooperation agreement with designated hospitals for special diseases nearby to establish a green passage for the elderly with special diseases to meet their medical needs.

\subsection{Increase Emotional and Social Support and Establish a Psychological Counseling Department}

Due to long-term separation from family and friends, the elderly in nursing homes are more likely to experience negative emotions such as loneliness and depression than those living at home [13]. Family's regular visits and contact with family members can reduce the occurrence of negative emotions of the elderly, hence nursing homes should actively communicate with the children of the elderly and advocate their children to make more phone calls and take more visits so as to understand their mental state and living conditions. Previous studies have shown that rich social activities play an important role in improving 
the mental health of the elderly in nursing homes [14]. Therefore, nursing homes should organize diversified social activities and mobilize the interest of the elderly to participate, in order to enrich their daily life, to strengthen their communication, and to establish a harmonious living atmosphere. Moreover, nursing homes should also establish psychological counseling departments with professional psychologist, and active control over their psychological problems to improve their mental health.

\subsection{Introduce Professional Talent Team in Elderly Nursing and Strengthen Knowledge and Skills Training of Carer}

The shortage of professional talents in nursing homes will seriously affect the provision of medical-nursing integrated services. Therefore, nursing homes should make efforts in salary, benefits and career development to encourage nursing professionals to engage in caring for the elderly so as to change the shortage of nursing staff in nursing homes [15]. This research found that in-service caregivers in nursing homes have low levels of education with a lack of professional capabilities. Therefore, in addition to introducing nursing professionals, it is also necessary to attach importance to training and establish the certification system, the professional skill standards and the operating norms [16], so the nursing homes also should strengthen on-the-job training, and regularly provide nursing knowledge and skills training to caregivers in order to improve their work abilities. In addition, it is necessary to increase the training of humanistic care for caregivers to improve the happiness of the elderly.

\subsection{Have a Scientific Guidance for Rational Diet and Provide Diversified Diet}

This research found that the elderly in nursing homes are dissatisfied with their diets, mainly due to poor taste and unbalanced collocation. Relevant studies have found that the unbalanced diet of the elderly in nursing homes can cause malnutrition, which will seriously affect their health [17]. In view of this, in order to improve their health status, nursing homes should pay attention to the diet of the elderly, have a scientific guidance for rational diet, and highlight the characteristics of "medicine" in integration of medical and nursing, so nursing homes should have professional nutritionists to guide scientific food collocation and seasonings, not only pay attention to color, smell and taste, but also regularly change the dishes to meet the needs of the elderly; should establish health records, classify and manage the elderly with special dietary needs, and scientifically prepare meals according to the dietary requirements of doctors; should appropriately adjust the diet time and implement a combination of catering and ordering food to meet the individual needs of the elderly.

\section{Conclusion}

There are currently many shortcomings in medical-nursing integrated services of nursing homes, which cannot meet the needs of the elderly. Therefore, we 
recommended the following four measures to improve services so as to increase the satisfaction of the elderly: Firstly, clarify the content of medical services and improve the level of medical services; secondly, increase emotional and social support and establish a psychological counseling department; thirdly, introduce professional talent team in elderly nursing and strengthen knowledge and skills training of carer; fourthly, have a scientific guidance for rational diet and provide diversified diet.

\section{Acknowledgements}

We acknowledged these two nursing homes, and their staff for their support in one way or the other. We also acknowledged all elder people we interviewed for their contribution on the completion of this work.

\section{Funding}

The 2020 Education and Teaching Reform Research Project of the Department of Public Administration, School of Public Health and Management, Chongqing Medical University. The project number is GWGLXY202007.

The 13th Five-Year Key Discipline Funding Project of Nursing Science of Chongqing Education Commission, project number is $2019 \mathrm{hlxk} 15$.

\section{Conflicts of Interest}

The authors declare no conflicts of interest.

\section{References}

[1] National Bureau of Statistics (2020) Statistical Communique of the People's Republic of China on the 2019 National Economic and Social Development. http://www.stats.gov.cn/tjsj/zxfb/202002/t20200228_1728913.html

[2] Chongqing Bureau of Statistics (2020) Economic Performance of Chongqing in 2019. http://tjj.cq.gov.cn/zwxx_233/ttxw/202003/t20200331_6846275.html

[3] Huang, J.Y. and Jia, L.X. (2019) The Changes of Family Support for the Aged and the Exertion ofFamily Support for the Aged in the New Era. Academic Journal of Zhongzhou, No. 12, 83-88.

[4] Xia, T.H. and Fan, L. (2018) Development Status Quo of Old-Age Mode of Combination of Medical and Health Care in China. Chinese Nursing Research, 32, 1691-1693.

[5] Tian, Y.T., Zhang, Y., Li, H.J., et al. (2020). Analysis on the Status Quo and Influencing Factors of Unmet Demand for the Elderly in the Combination of Medical Treatment and Care Institutions in Henan Province. Medicine and Society, 33, 9-13.

[6] Liu, M. (2019) Using an Example to Illustrate Colaizzi's Phenomenological Data Analysis Method. Journal of Nursing Science, 34, 90-92.

[7] Li, Z.H. (2015) The Research for the Life Quality of Elderly People in the Old-Age Care Institutions in the Background of the Advanced Stage of Aging. MD, East China University of Science and Technology, Shanghai.

[8] Wang, C.S., Wu, M.L.Y. and Zeng, T.Y. (2017) Experience of the Elderly Living in Medical-Nursing Combined Pension Institutions: A Qualitative Study. Chinese 
Nursing Management, 17, 605-610.

[9] Wang, L.J., Feng, Y. and Wang, C. (2017) Evaluating the Service Quality of the Nursing Institution for the Aged. Population and Development, 23, 96-102.

[10] Bai, Z.F. and Shen, J. (2018) Depression, Loneliness and Cognitive Function among Elderly in Medical and Elderly Care Institution. Nursing Journal of Chinese People's Liberation Army, 35, 7-12.

[11] Zhou, X.L., Jiao, Y.H. and Wang, C. (2019) Problems and Countermeasures in the Medical-Nursing Integrated Service System of Xi'an Elderly Care Institutions. Chinese Journal of Gerontology, 39, 1210-1213.

[12] Zhang, Y.J. (2019) The Old-Age Service System with Integration of Medical and Nursing Needs to Be Constructed Urgently. People's Tribune, 28, 102-103.

[13] Luo, M.L. and Ren, B.H. (2019) Differences in the Mental Health of the Elderly Under Different Pension Modes. Chinese Journal of Gerontology, 39, 227-229.

[14] Tian, J.L. (2018) The Mental Health Status of the Elderly in Nursing Homes and Its Influencing Factors. Chinese Journal of Gerontology, 38, 6087-6090.

[15] Wang, B.Y., Xu, M.J. and Wu, Q.J. (2018) Status Quo and Countermeasures for Developing Institutions Combining Old-Age Care and Medical Care in Guangxi. Chinese General Practice, 21, 3741-3745.

[16] Wang, H.T. (2019) Take a Holistic Approach to Promote the Development of Pension Services Integrating Elderly Care and Medical Services. Macroeconomic Management, 35, 34-38.

[17] Zhou, L.P., Sun, J.P., Yang, Z.L., et al. (2016) Research Progress on Nutrition Management of the Elderly in Elderly Care Institutions. Chinese Journal of Gerontology, 36, 753-755. 